\title{
Letters
}

Website: www.bmj.com

Email: letters@bmj.com

\section{Reasons for not seeing drug representatives}

They should be seen because they are a good resource

EDITOR-The role of drug company representatives is changing, but Griffith's advice not to see them would deprive general practitioners of a good resource, which would be costly to replace. ${ }^{1}$ They offer many useful services that may not be easily accessible from other sources in the wider NHS, including up to date information on products and the provision of papers relating to a particular product or disease.

As primary care groups develop, this contact with individual doctors is likely to diminish, but the representatives' role in helping with the development of a formulary in each primary care group could be vital. Their ability to supply up to date information about particular products is also of great benefit to hospital pharmacists in NHS hospital trusts, who are often responsible for maintaining the hospital formulary under the guidance of the drug and therapeutics committee.

Pharmaceutical representatives are frequently a vital financial resource in the provision of sponsorship for meetings as part of continuing professional development.

\section{Advice to authors \\ We prefer to receive all responses electronically, sent either directly to our website or to the editorial office as email or on a disk. Processing your letter will be delayed unless it arrives in an electronic form. \\ We are now posting all direct submissions to our website within 24 hours of receipt and our intention is to post all other electronic submissions there as well. All responses will be eligible for publication in the paper journal. \\ Responses should be under 400 words and relate to articles published in the preceding month. They should include $\leqslant 5$ references, in the Vancouver style, including one to the BMJ article to which they relate. We welcome illustrations. \\ Please supply each author's current appointment and full address, and a phone or fax number or email address for the corresponding author. We ask authors to declare any competing interest. Please send a stamped addressed envelope if you would like to know whether your letter has been accepted or rejected. \\ Letters will be edited and may be shortened. \\ www.bmj.com \\ letters@bmj.com}

Indeed, half of general practitioners' postgraduate education is sponsored by the pharmaceutical industry, and much of that sponsorship is initiated by the representatives. The standard of continuing professional development is unlikely to be maintained without that sponsorship.

Griffith suggests that doctors feel obliged to see representatives and that junior doctors need education on the pitfalls of doing so. There is no evidence for these statements. Indeed, younger doctors frequently have better skills in critical appraisal and are thus more likely to question the representative hard. If he or she does not have evidence based knowledge of the product then younger doctors are unlikely to use it. Doctors could, though, usefully be given education about the Association of the British Pharmaceutical Industry's code of practice, which spells out what doctors may and may not expect from representatives as well as the penalties for doctors who try to induce representatives to break the code.

Pharmaceutical representatives are well trained and obliged to pass an examination within two years of beginning work. They can be a valuable resource in the provision of information and papers. Rather than stop seeing representatives as Griffith advocates, doctors should turn the representatives' visit into a positive occasion, ask questions, demand information, and make use of them.

Richard Tiner medical director

Association of the British Pharmaceutical Industry, London SW1A 2DY

JJack@abpi.org.uk

1 Griffith D. Reasons for not seeing drug representatives. BMJ 1999;319:69-70. (10 July.)

\section{But doctors do see them: "freebies" seem} disproportionately important

EDITOR-Griffith has given several reasons for not seeing drug representatives. ${ }^{1}$ Many of the responses to his editorial on the $B M / \mathrm{s}$ website mention the role of "freebies" in bribing doctors to see drug representatives. An interesting psychological phenomenon is at work here, which is worthy of further study.

I recently had the fascinating experience of working on a drug company's stand at a psychiatry conference, where one of my functions was to give out pens and alarm clocks to delegates after they had filled in questionnaires. I was amazed at the lengths to which people would go to get one of these worthless trinkets. Many delegates stole them when my attention was distracted. One psychiatrist even got his 10 year old son to fill in a questionnaire on how he treated his schizophrenic patients in the hope that this would qualify him for an extra alarm clock.

The perceived value of these goods in the psychiatrists' minds was clearly far higher than their real value. This raises various questions. Does the phenomenon apply only to psychiatrists, or is it universal? Is it peculiar to medical conferences? If the phenomenon is more general, we could hypothesise that general practitioners are driven to see drug representatives by an irrational and irresistible urge to collect their freebies.

Adam Jacobs director

Dianthus Medical, Mitcham, Surrey CR4 3BA ajacobs@dianthus.co.uk

1 Griffith D. Reasons for not seeing drug representatives. BMJ 1999;319:69-70. (10 July.)

2 Electronic responses. Reasons for not seeing drug representatives. $e B M J$ 1999;319. www.bmj.com/cgi/ content/full/319/7202/69

\section{Companies have to encourage doctors to} prescribe their products

EDitoR-Despite Griffith's conclusions that seeing drug company representative increases workload and costs, ${ }^{1}$ not having contact with the representatives would present problems.

On the whole, drug companies aim to make most of the profit that can be gained by a new drug during the first few years, when it remains under patent. It is therefore vital to the company that widespread use of the drug starts during that period. For this to happen, doctors' awareness of a new product needs to be established. Much time, effort, and money are devoted to the promotion and marketing of the drug, and drug company representatives are a cornerstone of this process.

Without this marketing strategy the likelihood of a successful product launch is greatly diminished. As a result, there will be little profit gain and so no incentive for the drug companies to continue their research programmes to find newer and better drugs for the future.

The training that doctors receive should allow them to assess the information they are given by the representative. Is the drug truly new? Does the evidence prove that it is more effective than others? What are the side effects? The general public is often less well equipped to assess this information and vulnerable to promises of a cure. Consider what happened recently when the company that made a non-steroidal anti-inflammatory drug targeted patients 
rather than general practitioners with its marketing.

Blanket bans on new drugs, or a blinkered approach to innovative new treatments, not only deny existing patients the benefits of new drugs but damage the opportunities available to future patients. The NHS's response to sildenafil (Viagra), interferon beta, and, in our own specialty, ondansetron, propofol, and sevoflurane is counterproductive to patients' treatment today and damages future drug research.

Doctors are accustomed to working in teams. The pharmaceutical industry is part of that team, in the same way as nurses, physiotherapists, and hospital management are. We don't always see eye to eye with each other, but we spite ourselves and our patients if we won't even talk to each other. Without drug representatives' pens most NHS doctors couldn't write any notes, without their mugs we couldn't drink our coffee, and without their drugs we couldn't cure our patients.

P Dodd senior house officer in anaesthetic docdodd@hotmail.com

T Dexter consultant in anaesthetics and intensive care Department of Anaesthetics, Wycombe General Hospital, High Wycombe, Buckinghamshire HP11 2TT

1 Griffith D. Reasons for not seeing drug representatives $B M J$ 1999;319:69-70. (10 July.)

\section{Drug representatives have much to offer}

EDITOR-Times are changing, and doctors' workload is increasing in many ways. Griffith suggests that pharmaceutical representatives are contributing to this workload and ignores many positive aspects to the representatives' existence. ${ }^{1}$ He makes an assumption that only new products are promoted, that the information obtained can be accessed from different sources, and that promotion necessarily leads to waste. He is wrong.

Changes in established products are discussed as well as new products. Much information is passed on about therapeutic areas and disease as well as products for all areas. The representative is often the conduit between the health professional and the company's medical information department, the value of which is shown by the 26000 telephone inquiries and 6000 written inquiries that SmithKline Beecham Pharmaceuticals received last year from the medical profession.

As an example of increased cost attributable to contact with representatives Griffith cites the use of selective serotonin reuptake inhibitors. These drugs provide benefit to many millions of patients and are efficacious, cost effective, well tolerated, and safer in overdose than other treatments. Much more money is wasted on alternatives used at doses so low that they are tolerated but ineffective.

As we approach the new millennium a constructive, not an adversarial, approach between industry and health professionals is needed. Pharmaceutical representatives and the pharmaceutical industry have much to offer. We provide information and education, fund most research in the NHS, and provide altruistic support. In partnership with health professionals we can meet our common goal, improving the health of patients.

A G Benbow medical director

Clinical Research and Development and Medical Affairs, UK, SmithKline Beecham Pharmaceuticals, Welwyn Garden City, Hertfordshire AL7 1EY Alastair_G_Benbow@sbphrd.com

1 Griffith D. Reasons for not seeing drug representatives. $B M J$ 1999:319;69-70. (10 July)

\section{Summary of electronic responses}

Deciding whether to see or not to see drug representatives is difficult. Of the 20 electronic responses that we received to this editorial, 10 were explicitly in favour (nine of them being from doctors) and seven were against it. ${ }^{1}$ The main reasons for seeing drug representatives are free gifts, free meals, free travel, but also "educational support, ... research grants, ... [and] ... drug company sponsored trials" (C Booth).

Drug representatives also "tend to be more pleasant, respectful, and caring to doctors as a whole, or at least on the surface, than the general population" (P Ting).

Do drug representatives influence prescribing patterns? "I hope that most intelligent doctors are able to separate the 'wheat from the chaff' ... and not be too influenced by the free pens, scales, note pads, appointment slips, sphygmomanometers, otoscopes, stethoscopes, etc that aid our work greatly, not to mention meals, weekends, and other trips that can make life so much more pleasant" (J Senior)

But then "would companies spend so much if these efforts didn't work?" (S Reidbord).

There is also evidence "that the prescribing behaviour of French primary care physicians is influenced by drug promotion. Firm fidelity was associated with more dangerous prescribing, consistent with the finding that drug promotional information generally omits safety information" (J Coste).

\section{Electronic responses. Reasons for not seeing drug representatives. eBMJ 1999;319. www.bmj.com/cgi/ content/full/319/7202/69 (accessed 9 August 1999).}

\section{Postcodes don't indicate individuals' social class}

Editor-In their report Danesh and colleagues said that an individual's postcode of residence could be used as a marker for his or her social class. ${ }^{1}$ This inference was based on the association between income reported in a survey and estimated household income for postcodes supplied by a commercial company. The accompanying commentary by Ben-Shlomo and Davey Smith cautioned that researchers should not attribute population characteristics to individuals - the ecological fallacy. ${ }^{2}$ These authors questioned the meaning of the association reported by

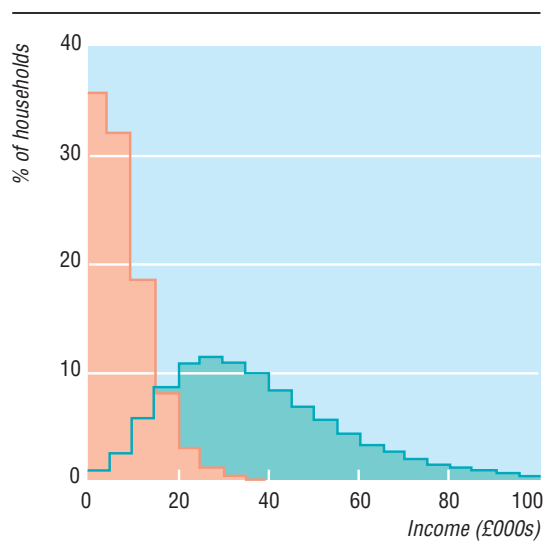

Income distribution in enumeration districts grouped by high or low average income. Each group contains $1 \%$ of all households in Scotland

Danesh et al and wondered how this correlation might change with different levels of aggregation or how it differs from associations found with indicators based on census data.

In Glasgow we are evaluating the utility of similar income data supplied by a different commercial company. ${ }^{3}$ Using data at higher levels of aggregation than used by Danesh et al and self reported household income for 2175 people in 1579 enumeration districts, ${ }^{4}$ we report that the correlation between enumeration district income and self reported income was $0.48 \quad(99 \%$ confidence interval 0.44 to 0.52 ). At postcode sector level this correlation was 0.38 (0.33 to 0.42 ). In comparison, the correlation between Carstairs scores (a deprivation indicator derived from census data) and self reported income at enumeration district level was $-0.44(-0.48$ to -0.39$)$ and $-0.35(-0.40$ to -0.30$)$ at postcode sector level. These associations are of similar magnitude to the correlation reported by Danesh et al. It is also worth noting that there was little difference in these correlations whether Carstairs scores or commercially supplied income data were used. On the basis of these findings, however, we do not suggest that enumeration districts or postcode sectors can be used as a proxy for an individual's social class. The figure shows the distribution of household income in two groups containing enumeration districts that are estimated to have the highest or lowest average income in Scotland. Each group was defined to contain $1 \%$ of all households. It shows a broad range of income with a substantial overlap in the two distributions. Such variation in individual income is likely to occur if postcodes were also used.

The ecological fallacy apart, the correlations we have found mean that it would be unsafe to assume an individual's social class on the basis of his or her address.

Philip McLoone research associate Anne Ellaway researcher

MRC Social and Public Health Sciences Unit,

University of Glasgow, Glasgow G12 8RZ 
1 Danesh J, Gault S, Semmence J, Appleby P, Peto R. Postcodes as useful markers of social class: population based study in 26000 British households. BMJ 1999;318:843-4

2 Ben-Shlomo Y, Davey Smith G. Commentary: Socioeconomic position should be measured accurately. BMJ 1999;318:844-5

3 CACI Information Services. PayCheck report. CACI's income model. London: CACI, 1997.

4 Economic and Social Research Council. ESRC health variations programme, ESRC award No L12830100174.

\section{Coronary artery disease varies seasonably in subtropics}

EDITOR-Seto et al's findings of seasonal variation in mortality from coronary artery disease in Hawaii ${ }^{1}$ are similar to our own findings in Hong Kong, a subtropical city.

Hong Kong has 6.2 million people residing and working in an urban and suburban area of about $1070 \mathrm{~km}^{2}$. In summer and autumn (May-October) the temperature is warm (mean $27^{\circ} \mathrm{C}$; range $22-30^{\circ} \mathrm{C}$ ); in winter and spring (NovemberApril) it is an average of $8^{\circ} \mathrm{C}$ cooler $\left(19^{\circ} \mathrm{C}\right.$; $7-27^{\circ} \mathrm{C}$ ).

As a single disease entity, coronary artery disease (ICD-9 410-414) emerged as the biggest killer in Hong Kong (3181 deaths in 1992). The sex difference in mortality is smaller than in other parts of the world; for the 40-69 age group the male to female ratio was 2.4 compared with 2.8 for the United States and 3.3 for England and Wales, and prevalence was greater in higher than in lower socioeconomic groups. The age standardised mortality (based on Segi's world populations ${ }^{2}$ ) from 1972 to 1992 stayed close to $60 / 100000$ for men and slightly above $30 / 100000$ for women-lower than in all countries except Japan, ${ }^{3}$ and less than half the rate in Hawaii.
The crude death rates for coronary artery disease, with three month moving averages (figure), show a strong seasonal variation and, compared with Hawaii, a stronger correlation with temperature $(r=-0.60 v-0.55)$, total hours of bright sunshine $(r=-0.30 v-0.27)$ and deaths from respiratory infection $(r=0.53 v 0.41)$, $\mathrm{P}<0.001$ for all. The difference between the peak month (January) and trough month (September) was greater than that in Hawaii $(37 \% v 22 \%)$ and the figures quoted for Scotland and New Zealand.

Seto et al interpret their data as showing that small changes in weather may affect mortality. In Hawaii, although monthly variation in temperature was small, the changes in hours of sunlight were marked and would be highly correlated with temperature.

The magnitude of seasonal variation in both coronary artery disease and respiratory deaths in the subtropical city of Hong Kong is stronger than that in the Hawaiian tropical climate and comparable to or greater than that in other temperate zones. Studies in seasonal variation of disease may shed light on the cause of terminal events in coronary artery disease.

CM Wong assistant professor

S Ma research fellow

TH Lam professor

AJ Hedley professor and head

Department of Community Medicine, University of Hong Kong, Hong Kong, China

1 Seto TB, Mittleman MA, Davis RB, Taira DA, Kawachi I. Seasonal variation in coronary artery disease mortality in Hawaii: observational study. BMJ 1998;316:1946-7.

Waterhous J, Mur C. Cancer incidence in fize Waterhouse J, Muir C. Cancer incidence in five continents. Vol 1992:675. International Agency for Research on Cancer,

3 Department of Health, University of Hong Kong. Coronary heart disease in Hong Kong. In: Public health report No 1: a new approach to public health report, coronary heart disease and lung cancer. Hong Kong: Department of Health, 1994:14-32.

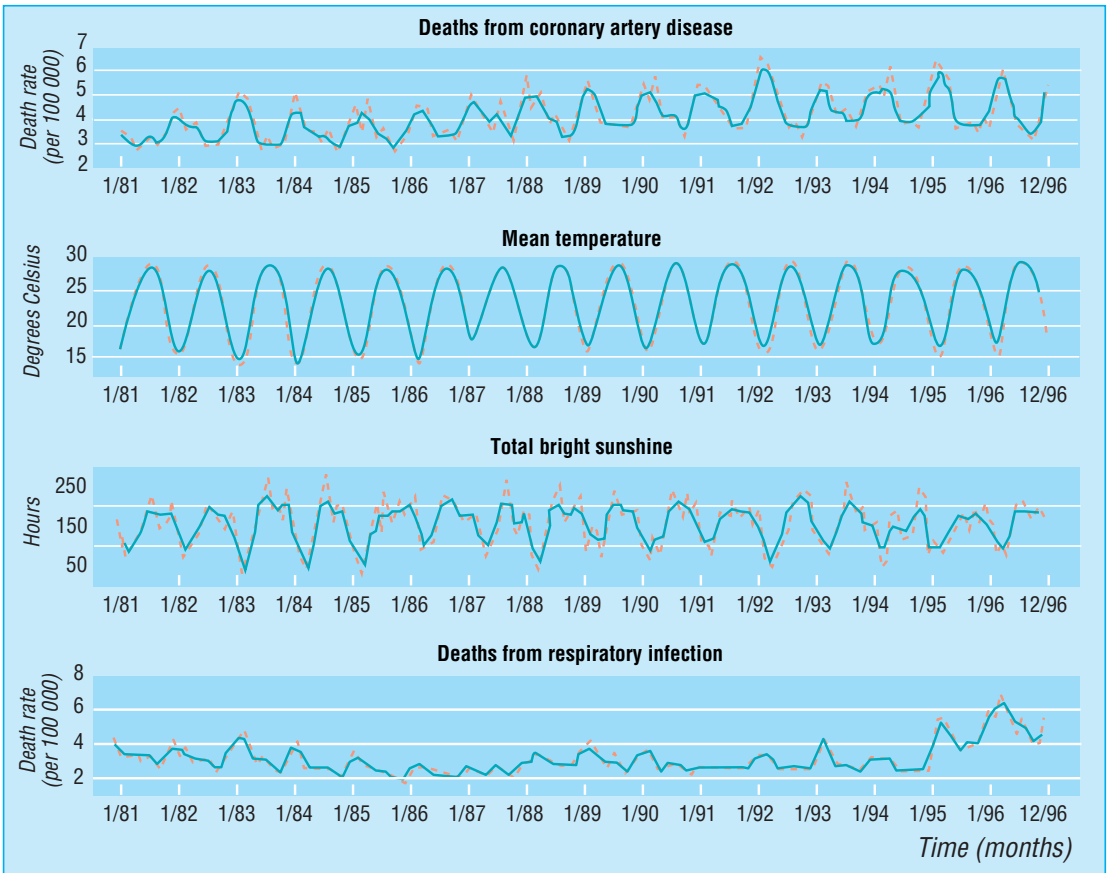

Seasonal variation (broken line shows three month moving average) in monthly death rates from coronary artery disease, with average temperature, hours of sunlight, and deaths from respiratory infection

\section{Acute urinary retention in men}

\section{Management is more complex issue than was described}

EDITOR-Emberton and Anson's review of acute urinary retention was timely and informative. In part of it they focused on the use of finasteride to reduce the risk of the disease. ${ }^{2}$ We disagree with them that the continuous administration of finasteride for four years is probably warranted in men with large prostates, moderate to severe symptoms, and poor urinary flow rates.

Firstly, the cost implications are enormous. To prevent one event (acute urinary retention or prostatectomy) 15 patients would have to be treated for four years at a cost of $£ 19475 .{ }^{3}$ Secondly, the reduction in mean symptom scores with long term finasteride treatment is small (mean reduction 3.3 points) and not comparable with the results obtained after prostatectomy (mean reduction 19.4 points). ${ }^{4}$ Furthermore, what should happen after four years of treatment has not been established. Should finasteride treatment be stopped, with the probability of prostatic regrowth, or should patients take it for life? The answers are not known. We therefore conclude that long term finasteride is not efficient or cost effective in preventing acute urinary retention and that prostatectomy should remain first line treatment in such patients

The review also describes patients with drained bladder volumes of more than 1 litre and low detrusor pressures who have a worse outcome (failure of catheter removal or failure of prostatectomy). Most urologists would describe this group as having chronic urinary retention, although there are no agreed criteria defining this condition. Uniform standards are urgently needed to evaluate data and therefore compare different treatments.

Jeremy J Elkabir higher surgical trainee in urology the.elk@virgin.net

Anup Patel consultant urologist

Justin A Vale consultant urologist

Ross O'N Witherow consultant urologist

St Mary's Hospital, Imperial College of Science

Technology and Medicine, London W2 1NY

1 Emberton M, Anson K. Acute urinary retention in men: an age old problem. BMJ 1999;318:921-5. (3 April.)

2 McConnell JD, Bruskewitz R, Walsh P, Andriole G, Liebe $\mathrm{M}$, Holtgrewe HL, et al. The effect of finasteride on the risk of acute urinary retention and the need for surgical treatment among men with benign prostatic hyperplasia. $N$ Engl J Med 1998;338:557-63.

3 Proscar: basic NHS cost. Monthly Index of Medical Specialities (MIMS) 1999;4:231

4 Emberton M, Neal DE, Black N, Fordham M, Harrison M, McBrien MP, et al. The effect of prostatectomy on symptom severity and quality of life. $B r \quad J$ Urol $1996 \cdot 77 \cdot 233-47$

\section{Authors' reply}

EDITOR-The principal concern of Elkabir et al relates to the cost of preventing one episode of acute urinary retention by use of finasteride. Unfortunately, their calculation was incorrect. Their mistake was to apply the overall treatment effect (finasteride $v$ placebo) to their analysis rather than calculate the numbers needed to treat for the group 
of men whom we deliberately specified in our review. We suggested that finasteride might be of use in those men at increased risk-not overall risk. In other words, those men with large prostates, high symptom scores, and low flow rates. In treating men with symptoms a $50 \%$ risk reduction for long term complications is achieved in addition to the health gain conferred by a reduction in symptoms. The analysis of Elkabir et al highlights the danger of "back of the envelope" economic assessment. An evaluation more in line with Drummond and Jefferson's guidelines for economic submissions to the $B M{ }^{r}$ was recently proposed. By analysing decisions based on models in which transitions were triggered by urological events, non-surgical failure, and natural mortality over a two year time frame, Albertsen et al concluded that finasteride showed cost savings compared with terazosin in appropriately selected patients. ${ }^{2}$ These cost savings were largely due to a reduction in the rates of acute urinary retention in men and the need for prostate surgery. Moreover, their findings seemed to be robust over a range of model assumptions and costs.

The other points of Elkabir et al were both raised and answered by them. Firstly, no one would argue that drug treatment and prostatectomy confer the same reduction in symptoms. Secondly, we, like Elkabir et al, cannot comment with any authority on intermittent treatment as no trials have addressed this question. Finally, the patients who had high volumes of urine drained from the bladder at the time of catheterisation were in sudden, painful retention of urine. Most people would call this acute retention of urine.

Mark Emberton senior lecturer in oncological urology Institute of Urology and Nephrology, University College Hospital, London W1P 7PN

memberton@dial.pipex.com

Ken Anson consultant urologist

St George's Hospital, London SW17 0QT

1 Drummond MF, Jefferson TO. Guidelines for authors and peer reviewers of economic submissions to the BMJ. BMJ peer reviewers of

2 Albertsen P, Pellisier J, Lowe F, Girman C, Roehrborn C. Economic implications of effects of finasteride on the risk Economic implications of effects of finasteride on the risk of acute retention
1999;161(suppl):13.

\section{DEC methods for appraising new drugs}

\section{Are a foundation for the NICE appraisal committee}

EDITOR-Freemantle and Mason are quite right to explore the difficult task that the National Institute for Clinical Excellence (NICE) will face in appraising new drugs. ${ }^{1}$ However, it is disappointing that there was so much in their article which misrepresented the work of our development and evaluation committee (DEC), and no recognition of the considerable activity of the committee relating to different interventions that are not new.
One of the main summary points stated that: "New drugs should be appraised in terms of physical outcomes that mean something to doctors and patients." This principle is a major influence in all the deliberations of our development and evaluation committee. For example, in the recent appraisal of $\beta$ interferons for multiple sclerosis, our discussions gave far more weight to possibly becoming wheelchair bound than to proxy measures such as changes on multiple resonance imaging. The debate also considered the impact of relapses on patients and their families, together with a whole range of issues relating to carers, health service delivery, and the complex matter of both documented and hidden costs. This breadth of discussion is exactly what Freemantle and Mason are proposing in their section on systematic profiles and is a routine part of appraisal by a development and evaluation committee. They also advocate "including the right people"-for example general practitioners "if a drug will mostly be prescribed in primary care." Our committee includes two general practitioners and a lay member because we believe that their views are important across the whole range of interventions. The NICE appraisal committee is likely to do the same, including a broad range of interests.

With regard to getting all the information about new drugs, our development and evaluation committee aims to address focused questions about the application of new drugs within quite a short time frame, pointing out areas of uncertainty in the published literature, and giving an early "update category" when further information is likely to become available. It has been our experience that pharmaceutical companies have been rather slow to release information, which is often presented in a somewhat selective form, and which has not been subjected to peer review. For these reasons the committee is cautious about making decisions that may affect allocation of NHS resources on the basis of unpublished data.

Estimates of cost effectiveness are difficult, and "cost per QALY" ranges may be wide in an attempt to allow for all the possible variables and assumptions. However with the explicit "cost per QALY" thresholds $^{2}$ which our committee uses, a wide range does not influence our judgment unless it crosses one of the threshold values; in practice this seldom happens.

We hope that NICE will build on the experience of the development and evaluation committees in its appraisal work.

Bruce Campbell chairman

Robert Peveler vice chairman

Development and Evaluation Committee for the South East and South West Regions, Royal Devon and Exeter Hospital (Wonford), Exeter EX2 5DW

1 Freemantle N, Mason J. Not playing with a full DEC: why development and evaluation committee methods for appraising new drugs may be inadequate. $B M$ 1999;7196:1480-2. (29 May)

2 Stevens A, Colin-Jones D, Gabbay J. "Ouick and clean": authoritative health technology assessment for local health care contracting. Health Trends 1995;27:37-42.

\section{Are justified}

EDIToR-Freemantle and Mason ${ }^{1}$ cite the 1997 South and West Development and Evaluation Committee report on donepezil as an example of the limitations of the committee's methods. However, it is clear from their assertions that their reading was not up to the task.

They imply that information on quality of life was not made available by the manufacturers. In fact, the report makes clear that we obtained considerable unpublished information from Eisai and Pfizer. The quality of life scales used in the trials have very low face validity and were considered unfit for the purpose of informing the cost utility analysis. Direct measurement of quality of life in dementia is an area of great uncertainty. ${ }^{2}$

In deriving a cautious estimate of the possible cost utility of donepezil, we estimated duration of benefit in two ways: firstly, directly from the results of the phase III trials, which showed an absence of decline in cognitive function over six months (the limitations of this as a proxy for disease status were discussed); secondly, the difference in the cognitive scores between treatment and control groups was considered in the context of a longitudinal study of cognitive decline which confirmed the probable duration of benefit in a less differentiated population.

We then considered, using the index of health related quality of life, what the prevention of cognitive decline for six months might mean for patients. This calculation is acknowledged as being speculative, but amid the hype that surrounded the release of donepezil $^{4}$ it made a useful and explicit contribution to the debate. Seven clinical experts and the Alzheimer's Disease Society provided advice and comments during the preparation of the report, for which the committee itself acted as a final peer review.

Freemantle and Mason are therefore wrong in stating that "it is simply not possible to square the arbitrary costs per QALY estimates in the conclusion of the committee's report with the results provided by the trial." It is clear from the evidence that donepezil provides, on average, a modest benefit at high cost and that considerable uncertainty should surround this. What we were successful in doing for the development and evaluation committee was to clarify the evidence and, where evidence was lacking, to make judicious and explicit use of reasonable assumptions in order to inform the decisions of commissioners and clinicians at the time at which they were being taken.

Ken Stein consultant in public health medicine

North and East Devon Health Authority,

Barnstaple EX31 1RW

1 Freemantle M, Mason J. Not playing with a full DEC: development and evaluation committee methods for appraising new drugs maybe inadequate. $B M J$ 1999;318:1480-2. (29 May.)

2 Howard K, Rockwood K. Quality of life in Alzheimer's disease. Dementia 1995:6:113-6.

3 Stern Y, Hesdoffer D, Sano M, Mayeux R. Measurement of functional capacity in Alzheimer's disease. Neurology 1992:42:1689-96. 
4 Stein K, Milne R, Best L. Advertisements for donepezil. BMJ 1997;315:1623.

5 Best L, Stevens A, Colin-Jones D. Rapid and responsive health technology assessment: the development and evaluation process in the South and West region of England. J Clin Effect 1997;2:51-6.

\section{Horizon scanning is important for emerging health technologies}

EDITOR-Freemantle and Mason's paper contains several unsubstantiated statements about horizon scanning for new and emerging health technologies. ${ }^{1}$ Firstly they only mention horizon scanning for drugs, whereas the activity of the National Horizon Scanning Centre (contracted to provide advance notice to the Department of Health of significant emerging technologies) covers diagnostic tests, imaging techniques, genetic testing and therapies, biotechnology, biomaterials, medical implants and other devices, surgical techniques, and non-surgical therapies, among others.

The statement that horizon scanning may be an inefficient use of resources would be better informed if the authors knew anything about its costs or benefits. Regarding the opportunity costs, the idea that such resources could be better deployed in the rapid appraisal of drugs does not allow for the fact that you need to know what to appraise before you can commission such work. It was suggested that the National Institute for Clinical Excellence (NICE) become reliant on pharmaceutical companies informing them of significant new products and preparing in-house cost impact assessments not open to independent review; this is illogical given the authors' view on the involvement of health service personnel and the companies' likely bias.

Horizon scanning is especially important in relation to non-pharmaceutical advances: there is no mechanism for their coordinated early identification and their development may be rapid in comparison to new drugs. Non-pharmaceuticals are developed by a wide variety of different organisations, and effective developments may not be recognised without special attention being given to them.

Many other countries involved in health technology assessment have seen the need for the early identification and prioritisation of emerging technologies. Some are joining a developing European collaborative working group, EuroScan, to exchange information. In addition, the methods used within the Horizon Scanning Centre build on processes used within Britain ${ }^{2}$ as well as overseas $^{3-5}$; they are increasingly sophisticated and under continual scrutiny and revision.

The problem of devoting time to new drugs, such as lubeluzole, that are subsequently withdrawn or suspended is a recognised hazard for all early identification systems. Spending time investigating advances that are subsequently halted is preferable to missing the window of opportunity for important topics. The early identification of the neuraminidase inhibitors zanamivir and Ro64-0796 for the prevention and treatment of influenza has facilitated the development of a proposal for a systematic review as well as allowed early consideration of potential impact on the current immunisation programme. Without this early identification all levels of the NHS would be unprepared for their use.

Claire Packer senior lecturer in public health medicine C.Packer@bham.ac.uk

Dogan Fidan health economist

National Horizon Scanning Centre, Department of Public Health and Epidemiology, University of Birmingham, Birmingham B15 2TT

1 Freemantle N, Mason J. Not playing with a full DEC: why development and evaluation committee methods for appraising new drugs maybe inadequate $B M J$ 1999;318:1480-2 (29 May)

Stevens A, Robert G, Gabbay J Identifying new health care technologies in the United Kingdom. Int J Techol Assess Health Care 1997;13.59-67.

Giustim Internet information Trindade L, Topfer L-A, De Giusti M. Internet informatio sources for the identification of emerging health technologies: a starting

4 Ten Velden GHM. The identification of new health care technologies by the Health Council of the Netherlands. In J Technol Assess Health Care 1998;14:671-9.

5 Carlsson P, Hultin H, Törnwall J. The early experiences of a national system for the identification and assessment of emerging health care technologies in Sweden. Int J Techno Assess Health Care 1998;14:687-94.

\section{Paper has errors and omissions}

Editor-Freemantle and Mason's paper on reports for development and evaluation committees (DECs) contains several important errors and omissions. ${ }^{1}$ This reflects their non-involvement in such work and failure to consult either producers or consumers of the reports.

Firstly, development and evaluation committees' reports are designed for, and fit excellently, the particular purpose of informing difficult urgent commissioning decisions. $^{2}$ Without them such decisions would be made without supportive information. None of the 100 reports produced so far has been significantly contradicted by later evidence. The reports on olanzapine and donepezil are likely to be as durable (and are scarcely recognisable in Freemantle and Mason's account)..$^{3-5}$

Secondly, our systematic search, synthesis, and modelling is always accompanied by a thorough assessment of information quality Two committees formally use a grid grading information. ${ }^{2}$ Furthermore, the reports include a sensitivity analysis reflecting the quality of evidence. These procedures are at the core of evidence based practice.

Thirdly, overall cost, opportunity costs, and benefits are central to the evaluation process and will hardly be news to anyone involved in setting up the National Institute for Clinical Excellence (NICE).

Fourthly, though we try, wherever possible, to determine cost utility, this is far from being the only assessment. Costs, benefits, and risks are always listed ("profiled"). Estimates of cost per QALY (not undertaken lightly) are included, with explicit assumptions, to protect appraisals from vested interests which would wish to distort the results-something quite easily done with a "ball park" profile.

Fifthly, reports are produced not by a committee but by three teams of expert reviewers. These three groups have formed a collaboration, InterDEC (www.soton.ac. $\mathrm{uk} /$ interdec/), which avoids duplication and continually refines and develops review methodology. This includes taking into account a view on the balance between speed and detail which will be needed when the work is done for a high profile national body.

Sixthly, if possible we obtain unpublished information from pharmaceutical companies. Published data are often insufficient, but even where only published information is used, users of reports have been much better informed than had they been acting without such a report.

Seventhly, the criticism that reports for development and evaluation committees have insufficient coverage is misleading. When it is appropriate, we examine a range of interventions. Because policy makers usually need an answer rapidly, the value of a report that waited until a class of drugs had emerged might be lost through the delay. In the real world of NHS decision making, judgments also need to be made about the disutility of information that arrives too late to serve its purpose.

Andrew Stevens chairman

InterDEC, University of Birmingham, Birmingham B15 2TT

Nick Payne clinical senior lecturer in public health medicine

Ron Akehurst institute coordinato

Trent Institute of Health Services Research

Ruairidh Milne scientific director

John Gabbay director

Wessex Institute for Health Research and Development, University of Southampton

Amanda Burls director

Development and Evaluation Committee,

University of Birmingham

1. Freemantle N, Mason J Not playing with a full DEC: why development and evaluation committee methods for

2 Stevens, A, Colin-Jones, D, and Gabbay, J. "Quick and clean": authoritative health technology assessment for local health care contracting. Health Trends 1995;27:37-42. 3 Cummins C, Stevens A, Kisely S. The use of olanzapine as a first and second choice treatment in schizophrenia. Birmingham: University of Birmingham, 1998. (DPHE report No 10.)

4 Stein KW. Donepezil in the treatment of mild to moderate senile dementia of the Alzheimer type (SDAT). Report to the Development and Evaluation Committee. Bristol: NHS Executive South and West, 1997. (Report No 69.)

5 Pitt FA, Chilcott J, Golightly P, Sykes J, Whittingham M. A review of the use of donepezil in the treatment of Alzheimer's disreview of the use of donepezil in the rreatment of Aichermer's disease. Sheffield: Trent Institute for Health Services Research, Universities of Leicester, Nottingham and Sheffield, 1997. (G7/09.)

\section{Authors' reply}

EDITOR-Reports of development and evaluation committees have not been subject to formal evaluation. Neither are we aware of any independent assessment of their impact on decision making. Thus, it is surprising that they have been chosen from among many better known and respected candidates to provide the core process for National Institute for Clinical Excellence (NICE) appraisals. For example, the Drug and Therapeutics Bulletin is highly regarded by prescribers, and if developed it might provide a viable alternative with much 
experience and skill on which to base its processes.

Rather than proving durable and fit for purpose, reports have been shown to be flawed and based on strong assumptions. The report on donepezil hydrochloride concludes that "the range of cost-utility estimates is wide, ranging from approximately $£ 21,000$ to $£ 200,000$ per QALY," but to be credible these estimates should include infinity. The trials provided no evidence of increased survival attributable to donepezil (nor is this pharmacologically plausible) and direct measurement found no improvement in quality of life. ${ }^{1}$ Instead the development and evalution committee made strong assumptions that such a benefit must exist, rejecting the evidence from direct attempts to estimate quality of life because they lacked "face validity" (that is, the committee did not like the look of them) - a decision taken apparently in the knowledge of the absence of any benefit observed, and thus biased. Indeed, it is hard to see how a series of unvalidated simulation steps and strong assumptions can provide greater face validity than direct measurement in trials.

Similar presumptions were made when extrapolating from six week randomised trials to a claim that olanzapine provides "good evidence of excellent value for money." Both conclusions may simply reflect the prior beliefs of the committees, rather than an objective appraisal of the available evidence. The belief that the value of different interventions may simply be ranked is questionable. Previous work has shown that such an approach is flawed because of variations in methods and assumptions. ${ }^{2} 3$

The existence of a European association dedicated to horizon scanning does not, on its own, indicate the efficiency of this approach. If "winners" could be spotted in advance we would not need the considerable efforts of licensing bodies like the US Food and Drug Administration. Since drugs frequently fail in licensing trials, after the investment of millions of dollars in development and evaluation, limited resources for appraisal would be better targeted at the period immediately after licensing.

The key aim of our paper was to prompt discussion about how society should value health care. Unfortunately only those directly involved in the development and evaluation process or horizon scanning corresponded. In C S Lewis's modern fairytale That Hideous Strength the National Institute for Co-Ordinated Experiments (NICE) sets about solving the nation's problems through "pragmatometry," the complete application of science to society's problems, but loses sight of humanity. ${ }^{4}$ We should eschew simple but illusory numerical answers to complex decisions in favour of an explicit and participatory examination of the value of interventions.

Nick Freemantle senior research fellow

James Mason senior research fellow

Medicines Evaluation Group, University of York, York YO10 5DD
1 Freemantle N, Mason J. Not playing with a full DEC: why development and evaluation committee methods for appraising new drugs may be inadequate. BMJ 1999;318 1480-2. (29 May.)

2 Department of Health. Register of cost-effectiveness studies Leeds: Department of Health, Economics and Operational Research Division, 1994.

3 Mason J, Drummond M. Reporting guidelines for economic studies. Health Econ 1995;4:85-94.

4 Lewis CS. That hideous strength. London: Bodley Head, 1945.

\section{Drugs arriving in Kosovo need checking}

Editor-3As deputy head and consultants of the health department of EUAM (European Union Administration of Mostar) in 1995-6 we were impressed by Saunders's article concerning drug donations. ${ }^{1}$ In Bosnia these problems appeared for a variety of complex reasons that have been widely recognised..$^{2-4}$ The problem of private donations in former Yugoslavia was exacerbated by the country's proximity to the countries of the European Community. Though drugs arrived quickly and inexpensively, they arrived unchecked (table and $B M$ /s website, www.bmj.com). There may also have been a sense of impotence and guilt heightened by the fact that the war was too close to home to be ignored.

During our time in Bosnia the mayor of Mostar wrote to the European presidency and to all international non-governmental and governmental organizations of the European Union in an effort to put an end to unchecked donations. At the same time the city's health department forwarded a list of requirements for drugs that was updated monthly. Through accurate needs assessment, close contact with donor agencies, and cooperation with customs authorities it was possible to assess the appropriateness and quality of medical deliveries arriving in the city.

Although strict guidelines are necessary, ${ }^{5}$ as Saunders points out, they are not sufficient in the absence of effective coordination. It was our experience that $(a)$ local authorities fear running out of medical supplies and as a result medical authorities are

List of some useless drugs donated to Mostar during the war

\begin{tabular}{llr} 
Drugs & Form & Quantity \\
\hline Acetorphan & Tablets & 8000 \\
\hline Ambroxol & Tablets & 20000 \\
\hline Benzafibrate & Tablets & 22500 \\
\hline Buflomedil & Bottles & 800 \\
\hline Carbocisteine & Bottles & 200 \\
\hline Dapsone & Tablets & 1000000 \\
\hline Diphenhydramine & Bottles & 400 \\
\hline Echinacea purpurea & Bottles & 540 \\
\hline Etofenamate & Gel & 400 \\
\hline Guaiphenesin & Tablets & 240000 \\
\hline Mesoglycan & Suppositories & 4000 \\
\hline Methocarbamol & Tablets & 10000 \\
\hline Morniflumate & Tablets & 3500 \\
\hline Proxibarbal & Tablets & 2000 \\
\hline Ursodeoxycholic acid & Tablets & 7000 \\
\hline Valerian+melissa & Bottles & 1100 \\
\hline Verbenone & Suppositories & 2000 \\
\hline
\end{tabular}

pressed for drug donations without regard to quality; (b) it is difficult to find adequate premises to store drugs; $(c)$ qualified and motivated staff are lacking, a problem exacerbated by poor pay; $(d)$ there is a lack of coordination between local medical authorities and non-governmental and governmental organisations; $(e)$ once the drugs have been delivered to the medical institution it is very difficult to check how useful they have been - and this in turn renders the coordination of new donations more problematic; $(f)$ reliable local political authorities are lacking.

It is essential in the immediate postconflict situation that a capable and experienced working group be set up with well defined objectives in order to pinpoint urgent needs and see that these needs are met. Finally, serious consideration must be given to imposing sanctions against companies or institutions involved in dumping drugs.

Gian Luca Quaglio former deputy head, health and social services department, EUAM

Post-Graduate Medical School of Internal Medicine, University of Verona, 37134 Verona, Italy

Paolo Mezzelani former scientific adviser of project Department of Community Medicine and Psychosomatic Medicine, University of Verona mezzelani@cmib.univr.it

Claudi Cuchillo Consultant of Pharmaciens sans Frontières, France

Department of Biochemistry, Universitat Aut noma de Barcelona, Spain

1 Saunders P. Donations of useless medicines to Kosovo contributes to chaos. BMJ 1999;319:11. (2 Julv)

2 Hogerzeil HV, Couper MR, Gray R. Guidelines for drug Hogerzeil HV, Couper MR, Gray
donations. BMJ 1997;314:737-40.

3 Berckmans P, Dawans V, Schmets G, Vandenbergh D, Berckmans P, Dawans V, Schmets G, Vandenbergh D,
Autier P. Inappropriate drug-donation practices in Bosnia and Herzegovina, 1992 to 1996. N Engl J Med $1997 ; 337: 1842-5$

4 Autier P, Berckmans P, Schmets G. Inappropriate drug-donation practices in Bosnia and Herzegovina. $N$ Engl J Med 1998;338:1473-4.

5 World Health Organisation. Guidelines for drug donations. Geneva: WHO, 1996. (WHO/DAP/96.2.)

\section{Rates of anxiety and depression in African-Caribbeans may not reflect reality}

EDITOR-Shaw et al add welcome breadth to the literature concerning psychiatric disorders in African-Caribbeans. ${ }^{1}$ However, there are methodological problems which make interpretation of the results difficult.

Contrary to $B M J$ guidelines, there is no rationale for the choice of ethnic variables used. ${ }^{2}$ Hypotheses for why depression in the inner city should be expected to be related to Office for National Statistics' definitions of ethnicity may have led to the measurement of possible explanations or confounders such as financial worry, religion, housing, racism, and ecological variables such as community cohesion.

The use of a white European comparison group is problematic because of high rates of mental disorder in subgroups such as the Irish and refugees. ${ }^{3}$ Were white minority groups more likely to be cases? 
It is unclear how representative the African-Caribbean population is. Compared with other studies the proportion of Caribbean born African-Caribbeans is high. The mean age of the white and AfricanCaribbean groups were the same; however, other studies had to standardise rates for age because of the relatively low mean age of the African-Caribbean population. ${ }^{4}$ Half of those eligible took part in the study. The need for registration with a general practitioner may have led to fewer young African-Caribbeans being sampled. This could have led to errors in calculations of rates of depression.

The screening instruments that Shaw et al used have never been validated in an African-Caribbean population. Standardised instruments may underdiagnose depression in minority groups. Using a white European psychiatrist for subsequent interviews would not correct this error. ${ }^{4}$

The percentage of an ethnic minority group in an area affects the rate of mental illness. ${ }^{5}$ Hence rates gained from areas with a high concentration of people of Caribbean origin may not be generalisable. People of Caribbean origin were better educated than whites but were as likely to be unemployed and had similar incomes. Thwarted aspirations have been linked to higher rates of mental disorder. However, that better educated African-Caribbeans live in poor inner city areas shows that wider social forces are at work and underlines the need for a larger and more diverse sample to explain the findings. The questions that need to be answered are what would be the predicted prevalence of common mental disorders taking into account all known risk factors and what is the difference between this and that found for African-Caribbeans and whites? The answers could lead to the investigation of the extent to which culture, psychological, or social variables account for such differences.

Kwame McKenzie clinical lecturer

Institute of Psychiatry, London SE5 8AF

1 Shaw CM, Creed F, Tomenson B, Riste L, Cruikshank JK. Prevalence of anxiety and depressive illness and help seeking behaviour in African Caribbean and white Euroseeking behaviour in African Caribbean and white Euro-
peans: two phase general population survey. BMJ
1999:318:302-6. (30 January.) 1999:318:302-6. (30 January.)

2 McKenzie K, Crowcroft NS. Describing race. ethnicity and culture in medical science. BMJ 1996;312:1054.

Littlewood R, Lipsedge M. Aliens and alienists. London Routledge, 1997.

4 Nazroo J. Ethnicity and mental health. London Policy Studies Institute, 1997.

5 Halpern D. Minorities and mental health. Soc Sci Med 1993;36:597-607.

\section{Data on babies' safety during hospital births are being ignored}

EDITOR-Zander and Chamberlain state that "no evidence exists to support the claim that a hospital is the safest place for women to have normal births." They cite the report Where to be Born, published in 1994 by the National Epidemiology Unit.
In 1997 the Confidential Enquiry into Stillbirths and Deaths in Infancy published a survey of 19348 deaths in Britain occurring during 1994 and 1995, including 873 deaths due to intrapartum events. ${ }^{2}$ At that time $98.16 \%$ of all deliveries occurred in hospital. The chance of a normal baby dying during labour at term was 1 in 1561. The Royal Colleges of Obstetricians and Gynaecologists and of Midwives regard this risk as unacceptably high and are working to reduce it still further.

Data on home deliveries in the United States were published in $1995,{ }^{3}$ and data for home deliveries in Australia were published in $1998 .^{4}$ In the American study (a retrospective review of 11788 planned home births) the intrapartum and neonatal mortality among women intending to have a home birth at the onset of labour was 1 in 500. In a prospective American study of 1404 home births in 1994-5 the figure was 1 in 400 , and the authors regarded this outcome as good. ${ }^{5}$ In the Australian study, which included 7002 planned home births during 1985-90, the risk of intrapartum fetal death was 1 in 371 .

It is disappointing that no similar recent audit of the safety of home delivery in Britain is available. The figures from the United States and Australia are, however, strikingly similar; in the absence of current data from the United Kingdom they indicate that, for a normal birth, hospital delivery is now three to four times safer than home delivery for the baby.

Women should be able to choose between home and hospital delivery. They also have a right to accurate and up to date information.

James Drife professor of obstetrics and gynaecology University of Leeds, Leeds LS2 9NS

j.o.drife@leeds.ac.uk

1 Zander L, Chamberlain G. ABC of labour care: Place of birth. BMJ 1999;318:721-3. (13 March.)

2 Confidential Enquiry into Stillbirths and Deaths in Infancy. Fourth annual report: concentrating on intrapartum deaths 1994-95. London: Maternal and Child Health Research Consortium, 1997.

3 Anderson RE, Murphy PA. Outcomes of 11,788 planned home births attended by certified nurse-midwives. A retrospective descriptive study. J Nurse Midwifery 1995;40:48392.

4 Bastian H, Keirse MJNC, Lancaster PL. Perinatal deaths associated with planned home births in Australia: population based study. BMJ 1998;317:384-8.

5 Murphy PA, Fullerton J. Outcomes of intended home 5 Murphy PA, Fullerton $\mathrm{J}$. Outcomes of intended home
births in nurse-midwifery practice: a prospective descripbirths in nurse-midwifery practice: a prospc
tive study. Obstet Gynecol 1998;92:461-70.

\section{Midwives would prefer a vaginal delivery}

EDIToR-In 1997 a survey of female obstetricians found that $31 \%$ would choose to have a caesarean section rather than any other mode of delivery. ${ }^{1}$ To determine whether a similarly high proportion of other women who provided intrapartum care would choose a caesarean section as their preferred mode of delivery, we surveyed 135 female midwives.

The midwives (all practising) were directly approached and asked what mode of delivery they would choose if they were pregnant for the first time, had an uncomplicated singleton pregnancy with a cephalic presentation, and did not have any obstetric problems. All 135 women replied; 129 said that they intended to have a vaginal delivery.

The popular cited reason for the female obstetricians to have an elective caesarean was to protect the pelvic floor. Obstetricians rarely attend an uncomplicated delivery; they attend difficult deliveries and are called on to repair the more extensive episiotomies and perineal tears that can occur. Despite the reasons expressed, these traumatic deliveries may drive some female obstetricians to opt for an elective caesarean section.

Midwives are exposed to traumatic deliveries too but also attend uncomplicated deliveries. In addition, they are far more involved than obstetricians with the care in the puerperium of women who have had a caesarean section, when attending them postoperatively, and when at home. This makes them aware of the difficulties a woman has in nursing her child after a caesarean section in contrast to women who have normal vaginal deliveries. Thus midwives are probably in a superior position when it comes to making an informed choice regarding mode of delivery; they overwhelmingly aim to have a vaginal delivery.

Debate continues over whether women should be allowed a caesarean section on request. ${ }^{2}$ The discretionary practice of 31 of 85 female obstetricians based in London may have some influence in arguments over this but is not to be confused with whether women ought to request a caesarean section because 31 of 85 female obstetricians would have one. Some women deciding on their preferred mode of delivery may confuse the two issues.

The midwives surveyed were strongly in favour of aiming for vaginal delivery. We would hope that if an expectant mother with an uncomplicated pregnancy was aware of this it might help her make up her mind to aim for a vaginal delivery too. It is apparent to midwives that mothers who deliver vaginally are generally in a better condition to nurse their newborn babies.

Malcolm John Dickson specialist registrar Department of Obstetrics and Gynaecology, Wythenshawe Hospital, Manchester M23 9LT MalDickson@aol.com

Mark Willett specialist registrar

Department of Obstetrics and Gynaecology, Hope Hospital, Salford M6 8HD

Competing interests: None declared. 1 Al-Mufti R, McCarthy A, Fisk NM. Survey of obstetricians'
personal preference and discretionary practice. Eur J
Obstet Gynaecol Reprod Biol 1997;73:1-4.
$2 \begin{aligned} & \text { Paterson-Brown S, Amu O, Rajendran S, Bolaji II. Should } \\ & \text { doctors perform an elective caesarean section on request? }\end{aligned}$ BMJ 1998;317:462-5.

\section{Rapid responses}

Correspondence submitted electronically is available on our website www.bmj.com 